\title{
Application of Logical Planning Model for Public Transport Improvement Programs in the City of Addis Ababa
}

\author{
Mintesnot GEBEYEHU* and Shin-ei TAKANO**
}

\begin{abstract}
In countries where the development and improvement of public transport (PT) have many constraints, a Logical Planning Model that deals with a logical representation of a multi-dimensional process is essential. Addis Ababa, the capital of Ethiopia, is an area of low level of transit availability. The major modes of public transport in the city are buses and taxis and there is no rail transit within the city. Due to many factors, the existing bus service is of a low quality. Limited number of buses, the poor management and financial insecurity of the solitary government owned bus company and an inadequate cost recovery system are some of these factors. Taxis have many constraints in their operation including bad drivers' behaviour, excessive fare and high accident rate. Limited accessibility, lack of information systems, low frequency, the wider gap between demand and supply and inadequate infrastructure are identified as key problems of the overall public transport service. Therefore, this study has the objective of analyzing the existing situation and prospects of the public transport service and drawing strategic scenarios for future development and improvement. The Logical Planning Model is proposed to plan and evaluate improvement programs for public transportation in the city. Survey analysis, calculation of bus availability indices in each Traffic Analysis Zones (TAZ) and urban transport project documents are implemented for situational assessment and problem identification in order to use the Logical Planning Model.
\end{abstract}

JEL classification : R41, R52

Keywords: Addis Ababa City, BRT and LRT, Logical Planning Model, Inputs and Outputs, Public Transport

Abbreviations: AACG-Addis Ababa City Government, BRT-Bus Rapid Transit, CIBA-City Index of Bus Availability, ERA-Ethiopian Road Authority, ETB-Ethiopian Birr, GISGeographical Information systems, LRT-Light Rail Transit, LITA-Local Index of Transit Availability, LPM-Logical Planning Model, ORAAMP-Office for Revision of Addis Ababa Master Plan, PCE-Private Car Equivalent, PT-Public Transport, TAZ-Traffic Analysis Zone, USD-US Dollar, VOC-Vehicle Operating Cost

\section{Introduction}

Public transportation is an important element of day to day activities in Addis Ababa city because (a) it is a relatively affordable means of transportation and (b) infrastructure

* Department of Urban and Environmental Engineering, Graduate School of Engineering, Hokkaido University, Kita-13, Nishi-8, Kita-ku, Sapporo 060-8628, Japan

Tel : +81-011-706-6822, Fax : +81-011-706-6206, E-mail : minte@eng.hokudai.ac.jp

** Department of Urban and Environmental Engineering, Graduate School of Engineering, Hokkaido University, Kita-13, Nishi-8, Kita-ku, Sapporo 060-8628, Japan

Tel : +81-011-706-6205, Fax : +81-011-706-6205, E-mail : shey@eng.hokudai.ac.jp 
is not sufficient to promote private vehicle ownership and (c) reduction of environmental pollution and traffic accidents. Even though the role of public transportation is noteworthy, the service provision is not good enough and the demand is much greater than the supply. As the population and the number of passengers increase, the service should be expected to increase. However, this is not practically true in the city because of financial and managerial constraints. In the city of Addis Ababa, the public transportation modes are city buses and taxis. There is no rail transit within the city. It is noted that a reasonable number of residents walk for relatively short trips. Unlike other cities of the country, bicycle is insignificant because of topographic inconvenience. Buses provide about $40 \%$ of the public transport in the city where as taxis account for about $60 \%$. There is only one bus company with a network of 93 lines and it is an affordable means of transportation for the urban poor. The city is currently experiencing a horizontal growth but the bus service has not exhibited growth proportionate to this. The analysis results of the transit availability indices show that only the centre of the city is being served by the existing bus networks while urban expansion areas have low transit availability. Limited accessibility, poor information systems, low frequency and the gap between demand and supply are identified as key problems. Mobility in developing world is often characterized by travel demand that far exceeds supply (Georges B. Darido [4]) and Addis Ababa is not an exception to this reality. Demand for urban public transport services is growing the same as other third world cities (G.D. Jacobs, et al. [5]). Since the prevailing PT problems are multi-dimensional, Logical Planning Model is proposed to be useful tool for planning and evaluating improvement programs.

This paper is organized in 9 sections. The second section explains the background and the third section the methodology. Section 4 describes the theory regarding Logical Planning Model and section 5 presents the input condition for the stated model. Section 6 discusses the activities and output condition and section 7 explains the outcome depend on the results and general considerations in the pervious section. Section 8 and 9 explain the discussion of results and the conclusion respectively.

\section{Background}

Addis Ababa is the capital city of the Federal Democratic Republic of Ethiopia and is located at the centre of the country. Established in 1886, the city has experienced several planning changes that have influenced its physical and social growth. The area of Addis Ababa is 530.14 square kilometres. In 1982, Addis Ababa had a population of 1.3 million, representing $4 \%$ of the population of the country and nearly one third of all urban dwellers. The current population of Addis Ababa is about 2.57 million, which is about $3.9 \%$ of the population of Ethiopia. It also represents about $26 \%$ of the urban population of Ethiopia. Addis Ababa has an aggregate population density of 4,847.8 persons per square kilometre. Public transport in Addis Ababa consists of conventional bus services provided by the publicly owned Anbessa City Bus Enterprise, taxis operated by the private sector, and buses exclusively for the use of employees of large organizations. The role of bicycles in urban transport is insignificant (The World Bank African region scoping study [13]). The road network of Addis Ababa is limited in extent and right of way. Its capacity is low, on-street 


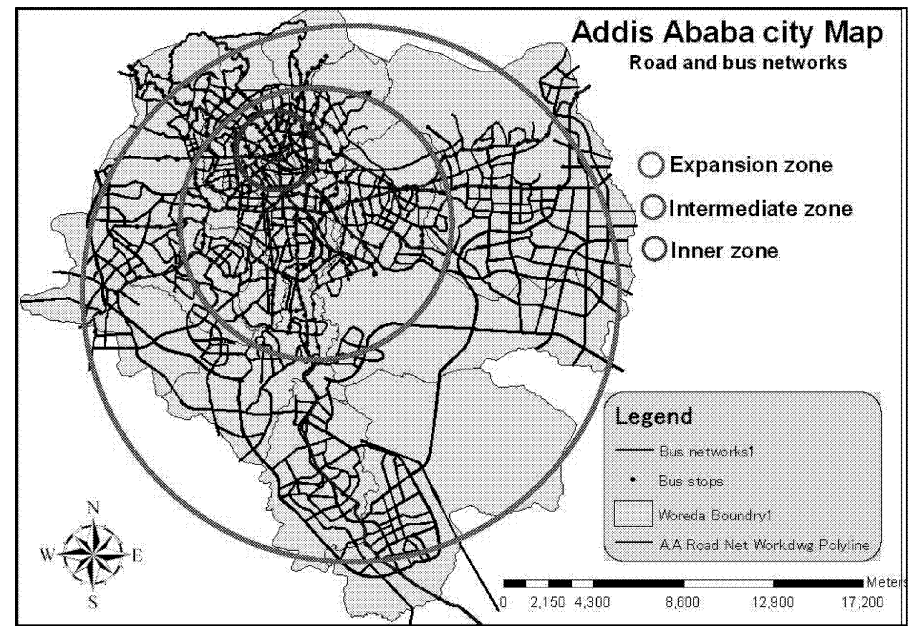

Figure 1 Location map and road network

parking is prevalent and the pavement condition is deteriorating. Despite a large volume of pedestrians, there are no walkways over a large length $(63 \%)$ of the network. This is the major concern, especially as it contributes to the increased pedestrian involvement in traffic accidents. According to the survey result, 'Work' is the predominant purpose of users and users are in middle age group. Accidents are high in Addis Ababa (10,189 in 2004). Pedestrians are the most vulnerable (67\%). Inadequate pedestrian facilities are a major cause of accidents (Ethiopian Road Authority (ERA) [3]).

\section{Methodology}

The research approach implemented in this study involves data collection, bus and taxi companies' data analysis and referring to urban transport project documents. We made a survey on bus service in September 2004 to grasp citizens' attitude. The data on spatial components (bus network, Traffic Analysis Zones, bus stops and other facilities) were digitized using Geographical Information Systems (GIS). The City Index of Bus Availability (CIBA) scores were calculated using capacity, frequency and service coverage components and the results were interpreted into GIS for rating each TAZ with bus service availability. The Logical Planning Model is implemented as a planning and evaluating tool for public transport improvement programs. Logical Planning Model (LPM) is introduced in this study as the combination of theory approach logic model and strategic planning model. Logic model describes the logical linkages among inputs, activities, outputs and what the intended outcomes (Motoki Asano, 2005 [9]) and the Strategic planning is a tool for organizing the present on the basis of the projections of the desired future. Both planning tools have several similarities yet with their own pitfalls so that their combined effect would provide a better result. The analysis result of the input condition gives the image of the existing situation. Based on that, the outputs and outcomes of public transport improvement programs have been indicated in this study. 


\section{Theory : Logical Planning Model}

There have been several planning models implemented for transportation projects. At the basic level, transportation planning is the process of answering four basic questions ; where are we now? where do we want to go? what will guide us? and how we will get there? (Michael D. May and Eric J. Mill, 2001 [7]). In this study the two widely used planning models (theory approach logic model and strategic planning model) were analysed and the Logical Planning Model is introduced. "Logical" here means capable of reasoning in a clear and consistent way. It is called "logical" because LPM shows the logical relationships among the resources that are invested, the activities that take place and the benefits or changes that result. One of the several pitfalls associated with strategic planning is that the plan may not turn out as expected because of changes in the environment in which the plan is supposed to operate where as theory approach logic model helps to develop appropriate and measurable indicators during the planning phase ; that is the key to a sound evaluation. Therefore, LPM is a systematic and visual way to present and share the understanding of the relationships among the resources to operate a program, the activities planned to do, and the changes or results hoped to achieve (W.K. Kellogg Foundation [15]). LPM has components like goal, inputs, activities, outputs, outcomes etc. 'Inputs' include the human, financial, organizational, and community resources a program has available to direct toward doing the work. 'Program activities (strategies)' are what the program does with the resources.

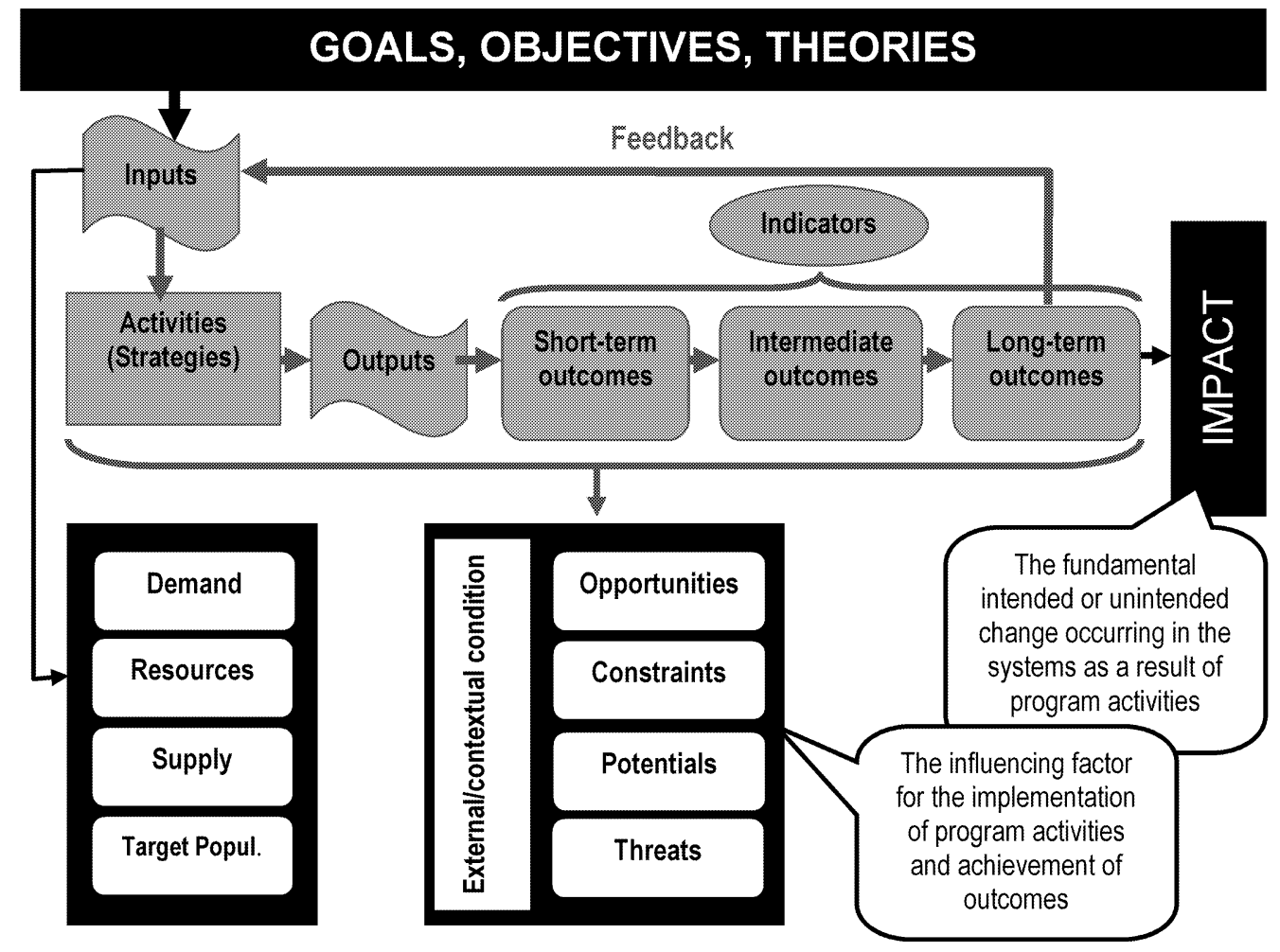

Figure 2 Logical Planning Model 
They are the processes, tools, events, technology, and actions that are an intentional part of the program implementation. These interventions are used to bring about the intended program changes or results. 'Outputs' are the direct products of program activities and may include types, levels and targets of services to be delivered by the program. 'Outcomes' are the specific changes in status and level of functioning, program participants' (users') behaviour, knowledge, skills etc. 'Indicators' are the specific items of information that track a program's success on outcomes. They are the measures selected as markers of success and are specific, observable, measurable characteristics or changes that represent achievement of the outcome.

Logical Planning Model is proposed for Addis Ababa city public transport improvement programs because it is a useful tool to deal with the multi-dimensional issues. The city's traffic and transportation problems are numerous and highly linked with the socio-economic condition of citizens, the financial and institutional matters, management and politics. Therefore, LPM gives the image of the current situation and the desired outcome that the public transportation improvement program would achieve. It follows a straight sequence yet capable of solving or representing the complicated process.

\section{Input Condition}

\subsection{Public transport demand}

According to the survey done in September 2004, the majority of the respondents use buses and taxi. Though walk is a significant mode, they don't use it for long trips. The reason for high public transport demand is that bus is an affordable mode and vehicle ownership level is very low. The data from Anbessa City Bus Enterprise shows that the numbers of bus passangers are increased year to year (figure 3). In a general travel pattern, for projected population of 5.56 million by 2020, a total of 7.7 million person trips are estimated to be generated within the city per day ; of which 'work' and 'education' are main purposes.

The indicative values for future transport development are studied under three conditions: pessimistic or constrained, normal or trend and optimistic. Different variables were

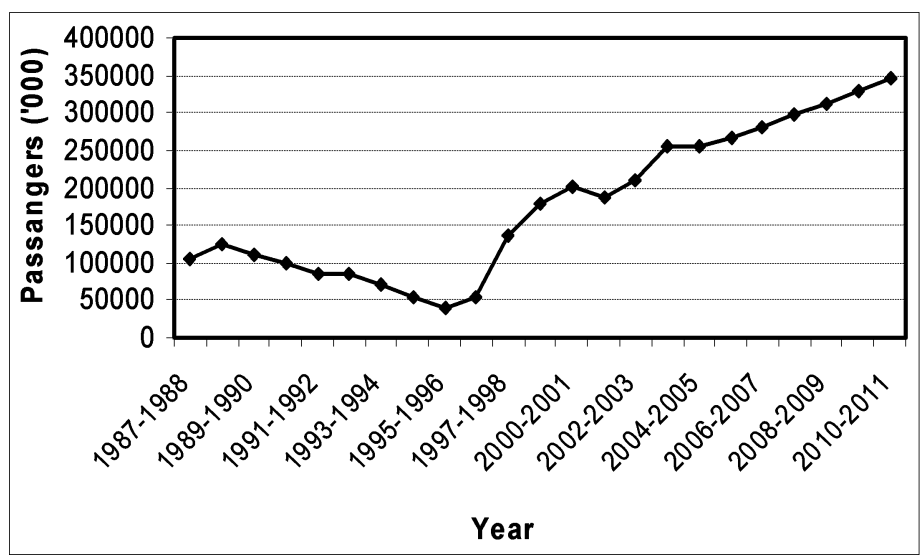

Figure 3 Bus passengers' growth trend 
Table 1 Variable measures for future public transport development

\begin{tabular}{|l|c|}
\hline \multicolumn{1}{|c|}{ Variables } & Demand indicators \\
\hline Population Size (2020) & 5.56 million \\
\hline Economy (Working Population Ratio) (2020) & $34.0 \%$ \\
\hline Per Capita Income (2020) & 290 Birr/month (existing: 110 Birr/month) \\
\hline Literacy (Student Enrolment) & $100 \%$ \\
\hline Mobility : & \\
\cline { 2 - 2 } \multicolumn{1}{r|}{ Overall (Per capita trip rate) } & 0.7 \\
\cline { 2 - 3 } Vehiar (Per capita trip rate) & $8 \%$ \\
\hline Motorization (Vehicle Growth in 2020) & $40 \%$ \\
\hline Modal Share (PT share of vehicle trips) & Medium Capacity (LRT/BRT) \\
\hline Public Transport Technology & High \\
\hline Density & Corridor Based \\
\hline Urban Form & Multi-nuclei \\
\hline Urban Structure & Easy Access \\
\hline Resources & High, Cooperative, Supportive \\
\hline Legal and institutional framework & \\
\hline Peoples Participation &
\end{tabular}

Source: ERA, 2005

selected to measure the future growth and these suggested that there would be an optimistic growth. The values of variables of development are given in table 1 . There would be a desirable growth and change takes place in the design period.

\subsection{Citizens' Attitude to public transportation}

Since the availability of data on the modal usage in general and citizens' mode preference and satisfaction with the current bus service in particular is poor, we made a survey in the city of Addis Ababa in September 2004. The questionnaire includes socio-economic variables as well as preference variables. The door-to-door survey was done for 750 respondents from three categories of societies: inner city residents, those living in intermediate zones and expansion area residents. According to the survey, the most preferred mode of transportation is identified to be bus. Buses are an affordable motorized means of transportation bearing in mind the economic condition of the residents. According to the survey on the transportation preference $44 \%$ (of 733 respondents) said that bus is strongly preferable in terms of cost. $47 \%, 7 \%$ and $2 \%$ said it is preferable, less preferable and non-preferable respectively when cost is concerned.

In terms of convenience, only $2 \%$ said bus is strongly preferable and when frequency or punctuality is concerned, $53 \%$ said it is preferable although a reasonable number $(29 \%)$ said it is less preferable. According to the survey of 710 respondents on the condition of the 


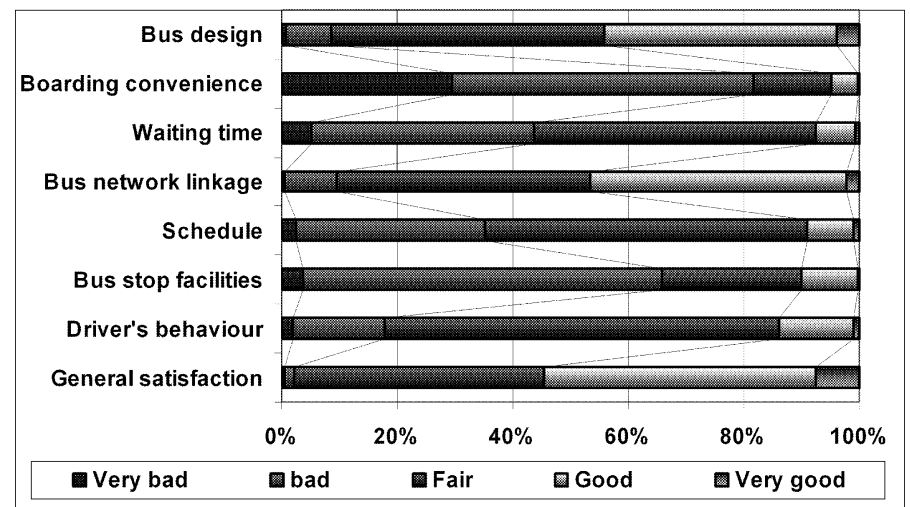

Figure 4 Citizens' satisfaction on the bus service

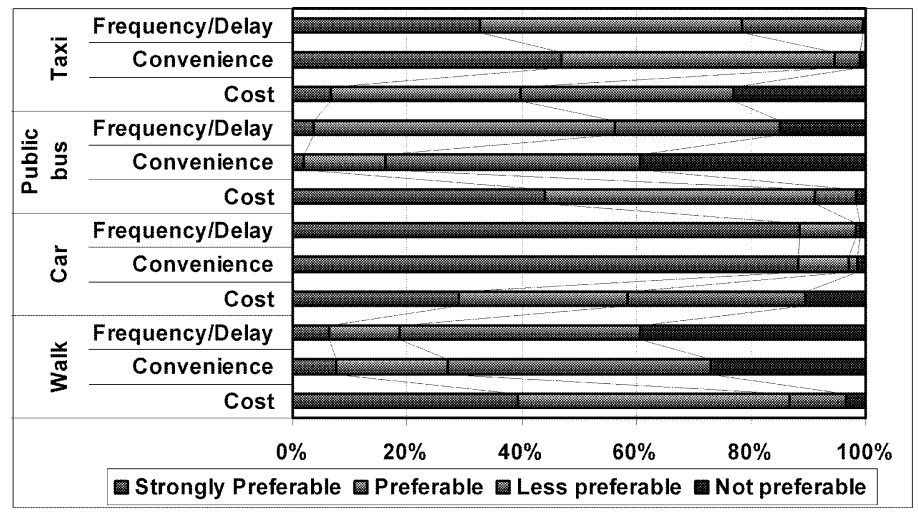

Figure 5 Citizens' mode preference parameters

current bus service, $43 \%$ said their general satisfaction with the bus service is fair and $47 \%$ felt that it was good respectively. Bus stop facilities and boarding convenience were considered to be bad attributes. According to the stated preference questionnaire on public transport for 300 respondents made by the Ethiopian Road Authority, 36\% of the respondents support the introduction of a Light Rail Transit system in the city.

\subsection{Existing bus service : City Index of Bus Availability (CIBA)}

The Local Government Commission of the United States, as an experimental measure, first introduced the Local Index of Transit Availability or LITA (Timothy Rood [12]). For Addis Ababa, we calculated the bus availability and bus service intensity as a City Index of Bus Availability or CIBA. It is focused on buses because the only transit option in the city of Addis Ababa is bus and there is no rail service. CIBA combines three aspects of transit service intensity: capacity, frequency and route coverage to rate each Traffic Analysis Zone. The capacity component uses seat-km divided by population; the frequency component is calculated as the number of transit vehicles per day and the route coverage component uses transit stops per square kilometre. After standardizing the index, the amount of transit service available is related to that area's population and to its land area. 
Data

Addis Ababa city is divided in to 308 Traffic Analysis Zones (TAZ) which have an average area of 1.56 square kilometres. The TAZ, the bus network and the bus stops were digitized using Geographical Information Systems (GIS). The bus capacity data (the number of seats) was collected from the solitary bus company, Anbessa City Bus Enterprise and the population of each zone is collected from the city's administration office. The area of each TAZ was calculated using GIS. Then the baseline data was prepared for the three components

1. Bus frequency and capacity baseline data: vehicles per day per line (total buses arriving at a typical stop per day) and vehicle capacity (No. of seats). After the database for the total buses arriving at a typical stop per day is prepared, then the capacity of the bus line is calculated using the following formula:

Total daily seats $=$ Buses per day at a specific stop $\times$ buses number of seats (capacity)

2. Population and land area (population density) baseline data

3. Compiled route length and transit stop data for each TAZ

Route length $=[$ length of two way route completely within the analysis zone $]$ $+[1 / 2 \times$ (length of route bordering the analysis zone) $]$

The bus stops in each analysis zone are counted in such a way that bus stops laying in the TAZ are counted as 'one'. In addition to this, stops falling along a boundary are counted as a half stop in each of the bordering analysis zones or it is counted as one fourth if the bus stop is located at the cross intersection of four zones

Number of stops $=[$ Number of bus stops completely within tract $]$

$$
\begin{aligned}
& +[1 / 2 \times(\text { Number of bus stop bordering analysis zone })] \\
& +[1 / 4 \times(\text { Number of bus stops touching } 4 \text { analysis zones })]
\end{aligned}
$$

\section{Calculation of CIBA Scores}

After compiling the baseline data, the three bus intensity scores were calculated as indicated below. After normalizing the results, the data was joined with the digital map using GIS, and the spatial intensity map is presented.

- Capacity score $($ every line in $\mathrm{TAZ})=[$ total daily bus seat $\times$ route length $] /[$ total population]

- Frequency score (every line in TAZ) = total number of buses, if the line has at least one stop in analysis zone, 0 otherwise

- Bus coverage scores (every TAZ) $=$ [number of bus stops $] /$ [area of the analysis zone $]$ The three scores are then summed up for each TAZ and the mean and the standard deviation are calculated so as to standardize the score.

Standardized score $=([$ capacity or frequency or coverage score $]-[$ mean of distribution])/[standard dev.]

The next step is to calculate the overall CIBA score of each analysis zone so that the result can be joined with the map to represent which areas are well served or under served by the existing bus supply. Weights are given for each parameter according to their importance. Since capacity involves service availability it gets 0.5 ; the coverage involves service extent it gets 0.3 ; and frequency aspect got 0.2 as it involves service quality; in accordance with 
service priority.

Overall CIBA score $=(0.5[$ capacity score $]+0.2[$ frequency score $]+0.3[$ bus coverage score $])$ At this point, rescaling the CIBA score is essential for greater ease of interpretation. To make all value positive, ' 5 ' was added to the overall score. Then the values are rated from A to $\mathrm{F}$ to see the level of bus service in each TAZ. Since ' 5 ' is found to be the mean value of the overall scores, the range from 4.5 to 5.5 gets ' $C$ '. If CIBA +5 score is over 6.5 the zone is rated as ' $\mathrm{A}$ ' (very high transit availability) and If CIBA +5 score lies within the range 5.5 to 6.5 the rating will be ' $\mathrm{B}$ '. For a score less than 4.5 the rating is ' $\mathrm{D}$ ' (no transit available).

CIBA results show that most areas in the city are not effectively covered by bus transit. $34 \%$ of the Traffic Analysis Zones have no bus transit available and $46 \%$ have very low transit availability. Only the centre of the city where commercial activities are abundant shows high scores because those areas serve as a transportation hub. From the GIS map of transit availability indices, it is clearly seen that the areas with low or no bus transit availability are in localities where the city is exhibiting trends of urban expansion and residential developments are underway. According to the recent structural synthesis map prepared by the Addis Ababa Master Plan Revision Office, those areas are strategic areas for city expansion development (Figure 11).

Places identified as having high density and high CIBA scores are to be target areas for public transport developments and improvements. They could be potential areas for bus or

Table 2 Baseline data of bus capacity

\begin{tabular}{|l|r|r|r|r|r|r|r|r|r|r|}
\hline BUS CAPACITY COUNT \\
\hline Route Number & $\begin{array}{c}\text { Route } \\
1\end{array}$ & $\begin{array}{c}\text { Route } \\
2\end{array}$ & $\begin{array}{c}\text { Route } \\
3\end{array}$ & $\begin{array}{c}\text { Route } \\
4\end{array}$ & $\ldots$ & $\begin{array}{c}\text { Route } \\
89\end{array}$ & $\begin{array}{c}\text { Route } \\
90\end{array}$ & $\begin{array}{c}\text { Route } \\
91\end{array}$ & $\begin{array}{c}\text { Route } \\
92\end{array}$ & $\begin{array}{c}\text { Route } \\
93\end{array}$ \\
\hline Buses per day [a] & 13 & 54 & 123 & 39 & $\cdots$ & 2 & 34 & 8 & 21 & 15 \\
\hline No. of seats per Bus [b] & 30 & 30 & 30 & 30 & $\cdots$ & 30 & 30 & 30 & 30 & 30 \\
\hline Total No. of seats [a] $\times[\mathrm{b}]$ & 390 & 1,620 & 3,690 & 1,170 & $\cdots$ & 60 & 1,020 & 240 & 630 & 450 \\
\hline
\end{tabular}

Table 3 Baseline data of number of bus stops

\begin{tabular}{|c|c|c|c|c|c|c|c|c|c|c|c|}
\hline No. & TAZ & Popul. & $\begin{array}{c}\text { Area } \\
\left(\mathrm{km}^{2}\right)\end{array}$ & $\begin{array}{c}\text { Density } \\
\left(\mathrm{pop} / \mathrm{km}^{2}\right)\end{array}$ & $\begin{array}{c}\text { Route } \\
1\end{array}$ & $\begin{array}{c}\text { Route } \\
2\end{array}$ & $\begin{array}{c}\text { Route } \\
3\end{array}$ & $\ldots$ & $\begin{array}{c}\text { Route } \\
88\end{array}$ & $\begin{array}{c}\text { Route } \\
89\end{array}$ & $\begin{array}{c}\text { Route } \\
90\end{array}$ \\
\hline 1 & W01K01* & 9,371 & 0.19 & 49349.96 & 0 & 0 & 0 & $\cdots$ & 0 & 0 & 0 \\
\hline 2 & W01K03 & 7,363 & 0.24 & 30785.26 & 0.25 & 0 & 0 & $\cdots$ & 0.25 & 0 & 0 \\
\hline 3 & W01K04 & 11,379 & 0.32 & 36060.06 & 1.25 & 0 & 0 & $\cdots$ & 1 & 0 & 0 \\
\hline$\ldots$ & $\ldots$ & $\ldots$ & $\ldots$ & $\ldots$ & $\cdots$ & $\cdots$ & $\cdots$ & $\cdots$ & $\cdots$ & $\cdots$ & $\cdots$ \\
\hline$\cdots$ & $\cdots$ & $\cdots$ & $\cdots$ & $\cdots$ & $\cdots$ & $\cdots$ & $\cdots$ & $\cdots$ & $\cdots$ & $\cdots$ & $\cdots$ \\
\hline 306 & W28K03 & 17,000 & 8.22 & 2068.64 & 0 & 0 & 0 & $\cdots$ & 0 & 0 & 0 \\
\hline 307 & W28K04a & 15,757 & 13.14 & 1199.25 & 0 & 0 & 0 & $\cdots$ & 0 & 0 & 0 \\
\hline 308 & W28K04b & 17,878 & 8.74 & 2044.87 & 0 & 0 & 0 & $\cdots$ & 0 & 0 & 0 \\
\hline
\end{tabular}

${ }^{*} W$-Wereda : called district, $K$-Kebele : this is the smallest administrative unit of the city (taken as TAZ) 
Table 4 Baseline data of bus route length $(\mathrm{km})$

\begin{tabular}{|c|c|c|c|c|c|c|c|c|c|c|c|}
\hline No. & TAZ & Popul. & $\begin{array}{c}\text { Area } \\
\left(\mathrm{km}^{2}\right)\end{array}$ & $\begin{array}{c}\text { Density } \\
\left(\mathrm{pop} / \mathrm{km}^{2}\right)\end{array}$ & $\begin{array}{c}\text { Route } \\
1\end{array}$ & $\begin{array}{c}\text { Route } \\
2\end{array}$ & $\begin{array}{c}\text { Route } \\
3\end{array}$ & $\ldots$ & $\begin{array}{c}\text { Route } \\
88\end{array}$ & $\begin{array}{c}\text { Route } \\
89\end{array}$ & $\begin{array}{c}\text { Route } \\
90\end{array}$ \\
\hline 1 & W01K01* & 9,371 & 0.19 & 49349.96 & 0 & 0 & 0 & $\cdots$ & 0 & 0 & 0 \\
\hline 2 & W01K03 & 7,363 & 0.24 & 30785.26 & 0.15 & 0 & 0 & $\cdots$ & 0.15 & 0 & 0 \\
\hline 3 & W01K04 & 11,379 & 0.32 & 36060.06 & 0.42 & 0 & 0 & $\cdots$ & 0.42 & 0 & 0 \\
\hline$\ldots$ & $\ldots$ & $\ldots$ & $\ldots$ & $\ldots$ & $\cdots$ & $\cdots$ & $\cdots$ & $\cdots$ & $\cdots$ & $\cdots$ & $\cdots$ \\
\hline$\cdots$ & $\cdots$ & $\cdots$ & $\cdots$ & $\cdots$ & $\cdots$ & $\cdots$ & $\cdots$ & $\cdots$ & $\cdots$ & $\cdots$ & $\cdots$ \\
\hline 306 & W28K03 & 17,000 & 8.22 & 2068.64 & 0 & 0 & 0 & $\cdots$ & 0 & 0 & 0 \\
\hline 307 & W28K04a & 15,757 & 13.14 & 1199.25 & 0 & 0 & 0 & $\cdots$ & 0 & 0 & 0 \\
\hline 308 & W28K04b & 17,878 & 8.74 & 2044.87 & 0 & 0 & 0 & $\cdots$ & 0 & 0 & 0 \\
\hline
\end{tabular}

${ }^{*} W$-Wereda : called district, $K$-Kebele $:$ this is the smallest administrative unit of the city (taken as TAZ)

Table 5 Sample of standardized CIBA Scores

\begin{tabular}{|c|c|c|c|c|c|c|}
\hline \multicolumn{6}{|c|}{ SAMPLE OF RATING TAZ WITH STANDARDIZED CIBA SCORES } \\
\hline TAZ & Capacity & Coverage & Frequency & OVERALL & Plus 5 & Rating \\
\hline W01K01 & -0.2320 & -0.0630 & -0.1029 & -0.3980 & 4.6020 & C \\
\hline W01K03 & -0.0541 & -0.0096 & 0.1418 & 0.0781 & 5.0781 & C \\
\hline W01K04 & 0.1128 & 0.3218 & 0.2162 & 0.6508 & 5.6508 & B \\
\hline$\ldots$ & $\ldots$ & $\ldots$ & $\ldots$ & $\ldots$ & $\ldots$ & $\ldots$ \\
\hline$\ldots$ & $\ldots$ & $\ldots$ & $\ldots$ & $\ldots$ & $\ldots$ & $\ldots$ \\
\hline W28K03 & -0.3335 & -0.2218 & -0.1798 & -0.7351 & 4.2649 & D \\
\hline W28K04a & -0.2760 & -0.2193 & -0.1583 & -0.6536 & 4.3464 & D \\
\hline W28K04b & -0.3335 & -0.2218 & -0.1798 & -0.7351 & 4.2649 & D \\
\hline
\end{tabular}

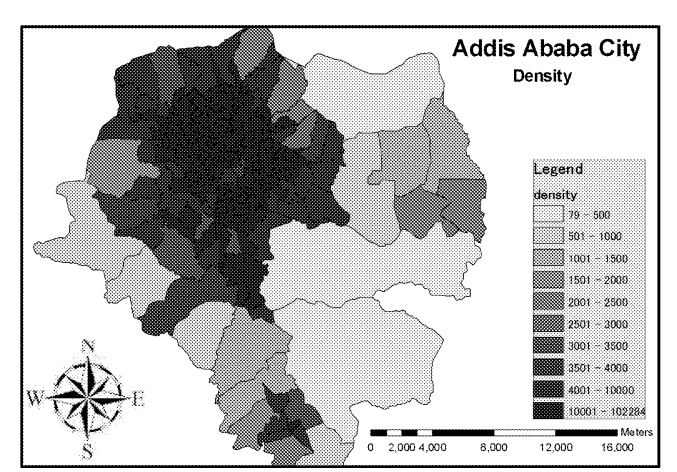

Figure 6 Density map of the city

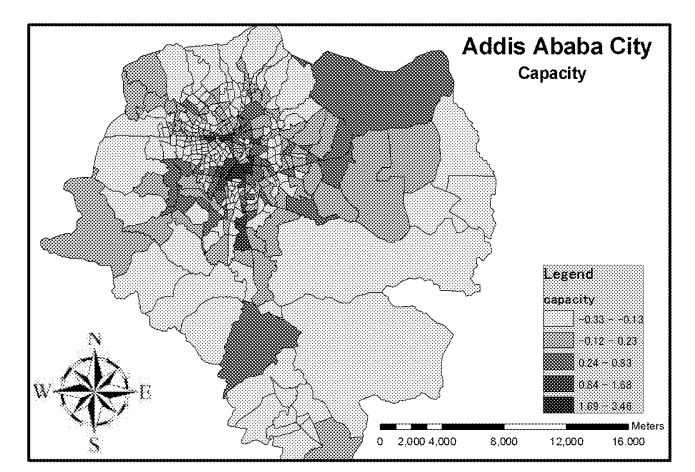

Figure 7 Capacity score 


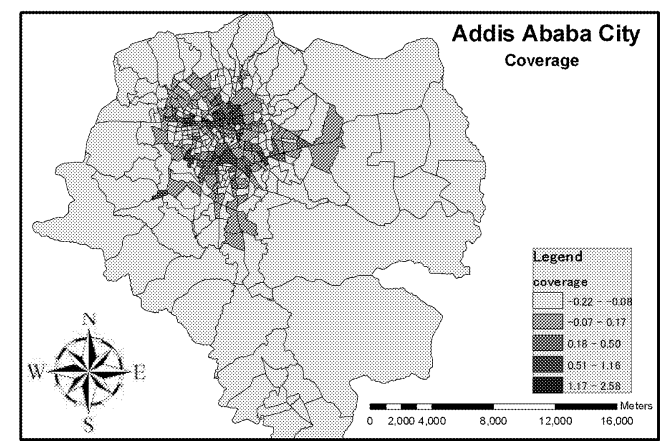

Figure 8 Coverage score

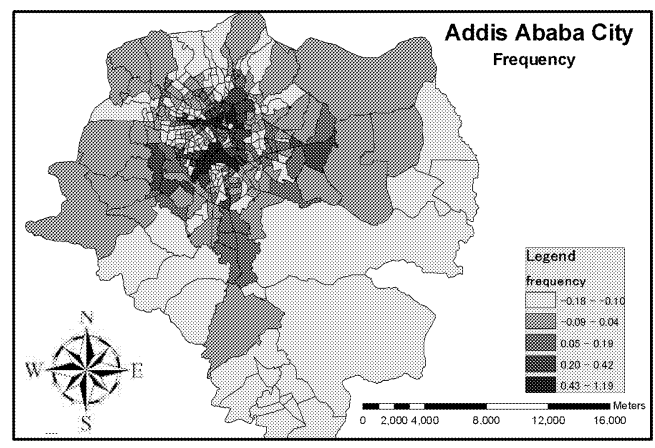

Figure 9 Frequency score
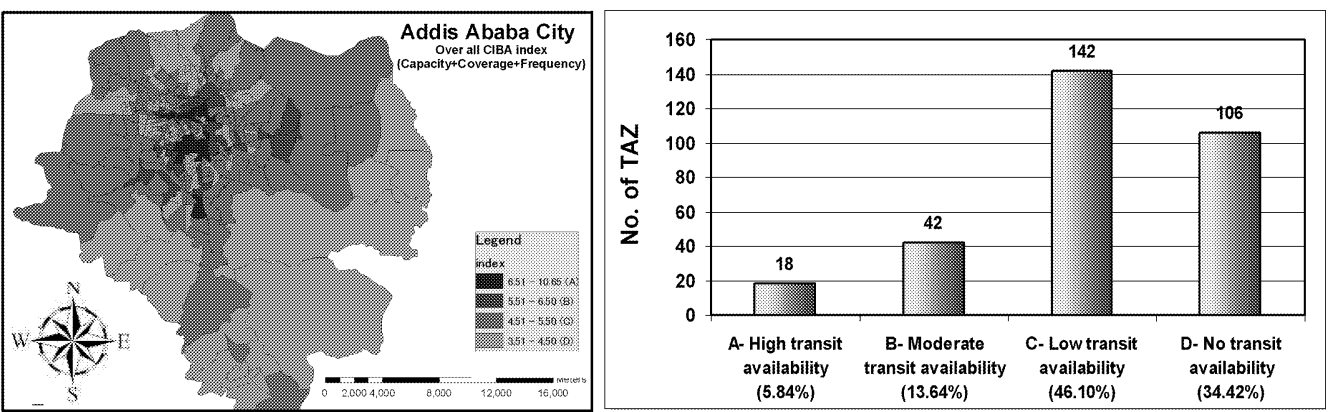

Figure 10 Rating CIBA score

rail terminal development. Infrastructure development and well-developed public transport information system are required in those areas. Areas with high density and low score are identified as areas where potential bus users are living so that transit service improvement is needed. In places where there is low density and high scores, infill developments are encouraged as a planning and policy measures. Creating attractions to those areas is essential so that they can be developed into transit-oriented places in the near future. Encouragement of development around the bus stops is to be the strategic solution. Areas with low density and low scores are potential zones for future expansion.

\subsection{Institutional framework and Legal Base}

The Addis Ababa City Government (AACG) has the charter to plan, develop and manage the city. It has a high degree of autonomy. Its functions are extensive and powers are exhaustive. However the AACG needs to get approval of the Federal Government for the levy of taxes. The Constitution of the Federal Democratic Republic of Ethiopia, the various proclamations of the Federal Government including the proclamation of the charter of establishment of Addis Ababa City Government (AACG) and the regulations issued by AACG govern the planning and development of all sectors in Addis Ababa, including transportation. The authority of the city government to issue regulations; the initiative of the federal and city governments are potentials for public transport service improvement programs. 


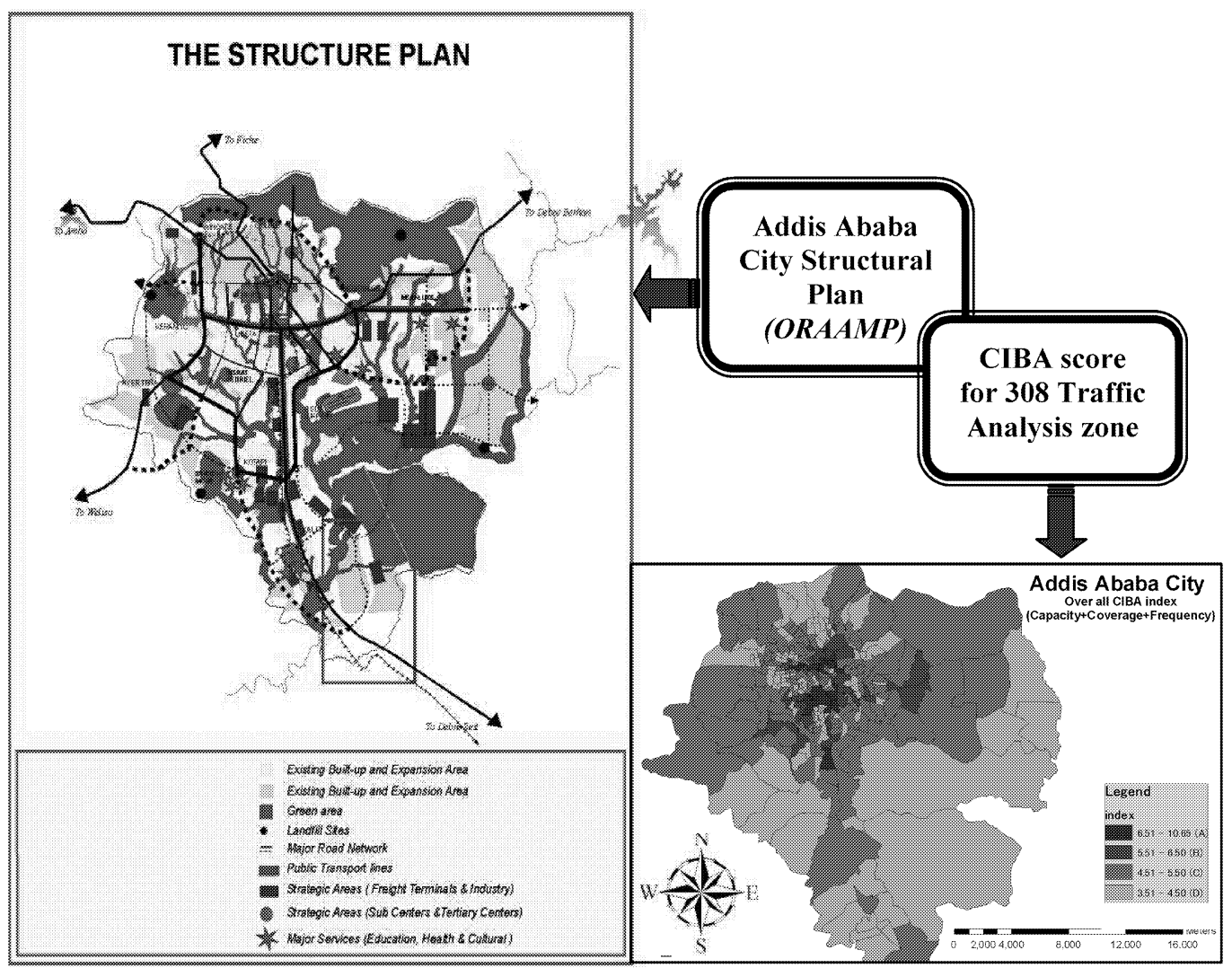

Figure 11 Addis Ababa city structural plan and CIBA scores

\section{Activities and Outputs}

There have been a number of strategic proposals included in the master plan project to solve the overall urban problems of the city of which public transport is among the concerns. However, there was less concern on strategic proposals for PT. Therefore, this study comes up with the most objective-oriented and specific activities to be undertaken as strategic measures to improve the condition of public transport. Output conditions are the proposed solution to solve the existing transport problems by dealing with the high demand. We built the output conditions depend on the results from the input condition and existing situational assessment. Because the existing bus and taxi system could not meet the demand, the new Bus Rapid Transit with separate lane and Light Rail Transit are recommended to be introduced in the city. The availability of potential capacity routes and the urban upgrading endeavours give space for the development. The route selection should be carefully chosen so that the rapid bus and train could cover the high travel demand areas. Even though the main output will be route generation for Bus Rapid Transit and Light Rail Transits, there are auxiliary activities to be undertaken as enlisted in table 6 for the better functioning of the proposed PT.

Building upon the output conditions and strategic scenarios, the conceptual framework 
Table 6 Activities to improve the public transportation

\begin{tabular}{|c|c|c|c|}
\hline Activity & Description & Opportunities & Limitations \\
\hline \multicolumn{4}{|c|}{ MAIN ACTIVITIES } \\
\hline $\begin{array}{l}\text { Bus Rapid } \\
\text { Transit }\end{array}$ & $\begin{array}{l}\text { Establishing a separate lane for } \\
\text { buses }\end{array}$ & $\begin{array}{l}\text { The availability of high capacity } \\
\text { roads in some areas, the urban up- } \\
\text { grading endeavours give space for } \\
\text { transportation development }\end{array}$ & $\begin{array}{l}\text { Bottle neck of roads } \\
\text { and dense develop- } \\
\text { ment at the urban } \\
\text { transportation cen- } \\
\text { tres, finance }\end{array}$ \\
\hline $\begin{array}{l}\text { Light Rail } \\
\text { Transit }\end{array}$ & $\begin{array}{l}\text { Develop rail transit so that it works } \\
\text { in coordination with the bus transit }\end{array}$ & $\begin{array}{l}\text { High travel demand, positive citi- } \\
\text { zens' attitude }\end{array}$ & $\begin{array}{l}\text { Electric power, high } \\
\text { capital cost }\end{array}$ \\
\hline \multicolumn{4}{|c|}{ AUXILIARY ACTIVITIES } \\
\hline $\begin{array}{l}\text { Public transit } \\
\text { privatisation }\end{array}$ & $\begin{array}{l}\text { Involvement of the private sector in } \\
\text { the public transport industry }\end{array}$ & $\begin{array}{l}\text { The City Bus Enterprise is ready for } \\
\text { privatization. Privatisation in the } \\
\text { transit sector is encouraged by the } \\
\text { Transport Authority (A.A. City } \\
\text { Trans. Authority [2]) }\end{array}$ & $\begin{array}{l}\text { Government will } \\
\text { have less or no con- } \\
\text { trol on price so that } \\
\text { excessive profit mak- } \\
\text { ing may occur }\end{array}$ \\
\hline $\begin{array}{l}\text { Bus service } \\
\text { coverage }\end{array}$ & $\begin{array}{l}\text { Expanding existing network and } \\
\text { increasing the number of buses }\end{array}$ & $\begin{array}{l}\text { The newly developed urban expan- } \\
\text { sion areas }\end{array}$ & Finance insufficiency \\
\hline $\begin{array}{l}\text { Land use } \\
\text { planning }\end{array}$ & $\begin{array}{l}\text { Encouraging compacted city devel- } \\
\text { opment }\end{array}$ & $\begin{array}{l}\text { There are identified vacant spaces } \\
\text { in the city }\end{array}$ & $\begin{array}{l}\text { The illegal develop- } \\
\text { ment and squatter } \\
\text { settlement expan- } \\
\text { sions }\end{array}$ \\
\hline Bus pricing & $\begin{array}{l}\text { Introduction of incremental fare sys- } \\
\text { tem or peak hour high bus fare }\end{array}$ & $\begin{array}{l}\text { Inelastic demand for bus by the } \\
\text { citizens }\end{array}$ & \\
\hline$\underset{\text { PT }}{\mathrm{PT}}$ & $\begin{array}{l}\text { Establishing new bus terminals, } \\
\text { express and feeder routes }\end{array}$ & $\begin{array}{l}\text { Places to be potential bus terminals } \\
\text { (with high density and high bus } \\
\text { availability index) }\end{array}$ & $\begin{array}{l}\text { Finance, skilled man } \\
\text { power }\end{array}$ \\
\hline Infrastructure & $\begin{array}{l}\text { Improving and widening infras- } \\
\text { tructure }\end{array}$ & $\begin{array}{l}\text { The number of vehicles and the } \\
\text { available infrastructure are not } \\
\text { compatible, world bank loan }\end{array}$ & $\begin{array}{l}\text { Requires huge invest- } \\
\text { ment }\end{array}$ \\
\hline $\begin{array}{l}\text { Public } \\
\text { transport } \\
\text { policy }\end{array}$ & $\begin{array}{l}\text { Drawing a public transport policy } \\
\text { that can regulate existing as well as } \\
\text { future transit development }\end{array}$ & $\begin{array}{l}\text { The need for the policy, the ongoing } \\
\text { studies as a part of the city's master } \\
\text { plan revision }\end{array}$ & \\
\hline $\begin{array}{l}\mathrm{PT} \\
\text { Information } \\
\text { System }\end{array}$ & $\begin{array}{l}\text { Establish strong PT Information } \\
\text { System with accurate pre-journey } \\
\text { and on-journey information }\end{array}$ & $\begin{array}{l}\text { Bus stops locations are suitable for } \\
\text { information display (high density) }\end{array}$ & $\begin{array}{l}\text { Financial problems } \\
\text { and weak manage- } \\
\text { ment. }\end{array}$ \\
\hline $\begin{array}{l}\text { Convenience } \\
\text { and comfort }\end{array}$ & $\begin{array}{l}\text { Introduce convenience and comfort } \\
\text { measures during waiting, boarding } \\
\text { and travelling. Improving the tow- } \\
\text { nscape for attractive travelling }\end{array}$ & $\begin{array}{l}\text { Suitable bus stop locations for bus } \\
\text { shade development }\end{array}$ & $\begin{array}{l}\text { Finance and man } \\
\text { power problems }\end{array}$ \\
\hline $\begin{array}{l}\text { High } \\
\text { occupancy } \\
\text { buses }\end{array}$ & $\begin{array}{l}\text { Introducing Double Decker buses } \\
\text { and extended buses }\end{array}$ & $\begin{array}{l}\text { The bus company is investigating } \\
\text { possibilities for introducing Double } \\
\text { Decker buses and extended buses }\end{array}$ & $\begin{array}{l}\text { Requires huge invest- } \\
\text { ment }\end{array}$ \\
\hline
\end{tabular}

was developed in such a way that the main centre of the city serves as potential main terminal for the PT and the secondary city centres are used as potential secondary terminals (figure 12). The LRT and BRT routes run along the south-north and east-west directions with one loop BRT. The axial feeder routes are serving for the regular buses and taxis. The terminals and stops will be integrated with the buses, taxis and parking areas. Depending on the conceptual frameworks and consideration of criteria, different public transport systems and their networks have been proposed (Refer table 7).

Criteria to select the alternatives are Capital cost, capacity and socio-environmental 

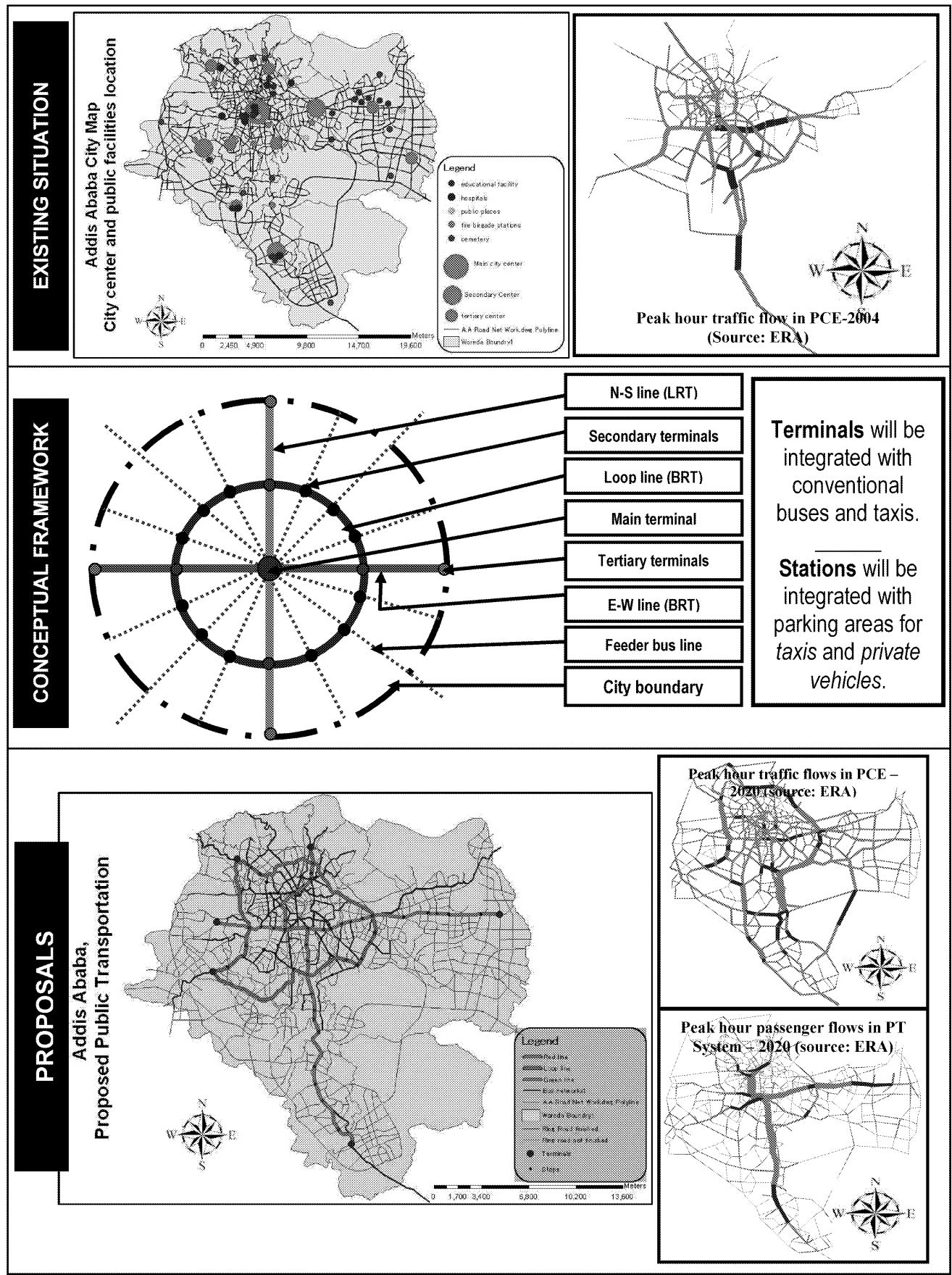

Figure 12 Existing situation, conceptual framework and proposed public transportation routes

benefits (Refer table 8). With Alternative 1; bus and taxi continuing (DO-NOTHING), at present levels performance, they would need to cater for a passenger load of 7 million trips per day. This would be equivalent to a fleet size of nearly 2,000 buses (present 524) and 
Table 7 Public transport proposals

\begin{tabular}{|c|c|c|}
\hline Scenario & Description & Remark \\
\hline Alternative-1 & Continuing the existing bus and taxi services & DO-NOTHING \\
\hline Alternative-2 & $\begin{array}{l}\text { Bus Rapid Transit with BUS PRIORITY LANE } \\
\text { a. BRT along North-South Corridor (BRT-NS) } \\
\text { b. BRT along East-West Corridor (BRT-EW) } \\
\text { c. Loop BRT linking secondary city centres (BRT-LOOP) }\end{array}$ & $\begin{array}{l}\text { Regular buses and } \\
\text { taxis will run on } \\
\text { links of arterial \& } \\
\text { collector roads }\end{array}$ \\
\hline Alternative-3 & $\begin{array}{l}\text { Medium Capacity Light Rail Transit (LRT) } \\
\text { a. LRT along North-South Corridor (LRT-NS) } \\
\text { b. LRT along East-West Corridor (LRT-EW) } \\
\text { c. Loop LRT linking secondary city centres (LRT-LOOP) }\end{array}$ & $\begin{array}{l}\text { Regular buses and } \\
\text { taxis will run on } \\
\text { links of arterial \& } \\
\text { collector roads }\end{array}$ \\
\hline Alternative- 4 & $\begin{array}{l}\text { The combination of Alternative } 2 \text { and } 3 \\
\text { a) LRT along North-South Corridor (LRT-NS) } \\
\text { b) BRT along East-West Corridor (BRT-EW) } \\
\text { c) Loop BRT linking secondary city centres (BRT-LOOP) }\end{array}$ & $\begin{array}{l}\text { Regular buses and } \\
\text { taxis will run on } \\
\text { links of arterial \& } \\
\text { collector roads }\end{array}$ \\
\hline
\end{tabular}

Table 8 Selection criteria for alternatives

\begin{tabular}{|c|c|c|c|}
\hline \multirow{2}{*}{ Scenario } & \multicolumn{3}{|c|}{ SELECTION CRITERIA } \\
\hline & Capital Cost & Capacity & $\begin{array}{l}\text { Social and } \\
\text { environmental benefit }\end{array}$ \\
\hline Alternative -1 & Low & Very low & Very low \\
\hline Alternative-2 & Medium $(20-50 \mathrm{METB} / \mathrm{km}) * \times 61 \mathrm{~km}$ & Low $(1,400-4,000 \mathrm{pass} / \mathrm{hr} / \text { way })^{* *}$ & High \\
\hline Alternative-3 & High $(70$ to $150 \mathrm{METB} / \mathrm{km}) \times 27 \mathrm{~km}$ & High $(6,000-15,000$ pass/hr/way) & Very high \\
\hline Alternative -4 & Medium & High & Very high \\
\hline \multicolumn{4}{|c|}{$\begin{array}{l}{ }^{*} \mathrm{METB} / \mathrm{km}=\text { Million Ethiopian Birr (USD } 1=8.8 \mathrm{ETB} \text { ), }{ }^{*} \mathrm{Pass} / \mathrm{hr} / \text { way }=\text { Passenger per hour per way } \\
\text { - The figures are estimated by the Addis Ababa Master Plan Revision Office } \\
\text { - Social and Environmental benefits include accident reduction, socio-economic change, travel pattern change } \\
\text { and environmental pollution reduction }\end{array}$} \\
\hline
\end{tabular}

35,000 taxis (present 12,500). This situation is not desirable from any point of view : there will be high congestion, intense competition and low productivity. For the user the travel times will be long, the quality of service will be poor and for the city or the community there will be high consumption of resources (land, energy, time, etc), increased accidents, deterioration of environmental quality, distorted urban form and structure, etc. It is important that not only the existing public transport are promoted to play their role but an additional system of higher capacity is introduced to form the basic component of the future PT of the city and cater to larger share of the travel demand.

The BRT has medium capital cost and low capacity while LRT exhibits high capital cost, high capacity and also high frequency. When one perceives the current national and regional situation, finance is the very big constraint. Ethiopian is one of the least developed countries and major developments are funded by loans and donations from foreign countries and financial institutions. Even if the rail development has high capacity and its environ- 
mental effect is very low, implementation seems infeasible from finance point of view. Therefore, for the planning period (2020), implementing the combination of the two systems will benefit in responding for the current demand (ALT-4).

\section{Route selection criteria for the proposed alternative}

The routes for the BRT and LRT are selected with two criteria: the road width and capacity and the land use (Refer figure 12). The road network is the one recommended in the Addis Ababa Master Plan 2000-2010 of which only arterial, sub-arterial and a few collector roads are considered as public transport networks. The road network is primarily of radial-ring pattern. The important radial corridors are the east-west corridor, northsouth corridor, the ring road and the new arterial links in the expansion areas. The total length of the road network is $731 \mathrm{~km}$ and this consists of $446.6 \mathrm{~km}$ of arterial roads, $124 \mathrm{~km}$ of sub arterial roads and $160.4 \mathrm{~km}$ of collector roads. The base year and forecasted traffic flow on the road networks are given in figure 12. The land use along corridors at the central parts of the city is compact and dense, while as one goes to the peripheries, scatter developments are observed. Land use along the main road in the south is dominated by industrial and commercial activities and along the main road in the west commercial and residential land uses are observed. Government institution and informal residential settlements are dominated along the main road to the east. The northern part of the city is dominated by residential developments mixed with commercial activities. Recently the city is developing with different city centres as it is proposed by the master plan. Developments are evidently emerging around these centres. The new PT route is generated in such a way that the main and secondary city centres are connected with terminals and the stations are located at areas where there are high trip generation.

\section{Outcomes}

Outcomes are the anticipated change on the program function, and it is not easy to quantify them. They can be derived from the input conditions, the activities and from general considerations. The three main stakeholders in the public transport are the community, the government and the transit operators on which the effects of the outcomes are manifested. The changes on environment and the land use are the physical indicators to count the success of the new PT.

Community: The community will be the first hand beneficiaries from the new PT system. It will bring the change in life style and it will make travelling enjoyable. There will be an economic lift up for the community as there emerges economic activities around terminals and stations. The introduction of the new Bus Rapid Transit and Light Rail System brings a considerable change in the travel pattern. Savings in passenger travel time due to higher frequency is one of the outcomes, and it would accrue to both users and non-users of public transport. Non-PT users would benefit indirectly in terms of savings in vehicle operating cost (VOC) due to reduced congestion on the road network as a result of the new BRT and LRT. Reduced waiting and boarding time, increased network coverage, increased conveniences are among the outcomes. According to the survey we made on September 2004 an average of 26 minutes bus frequency is observed on the existing bus service yet there exists 


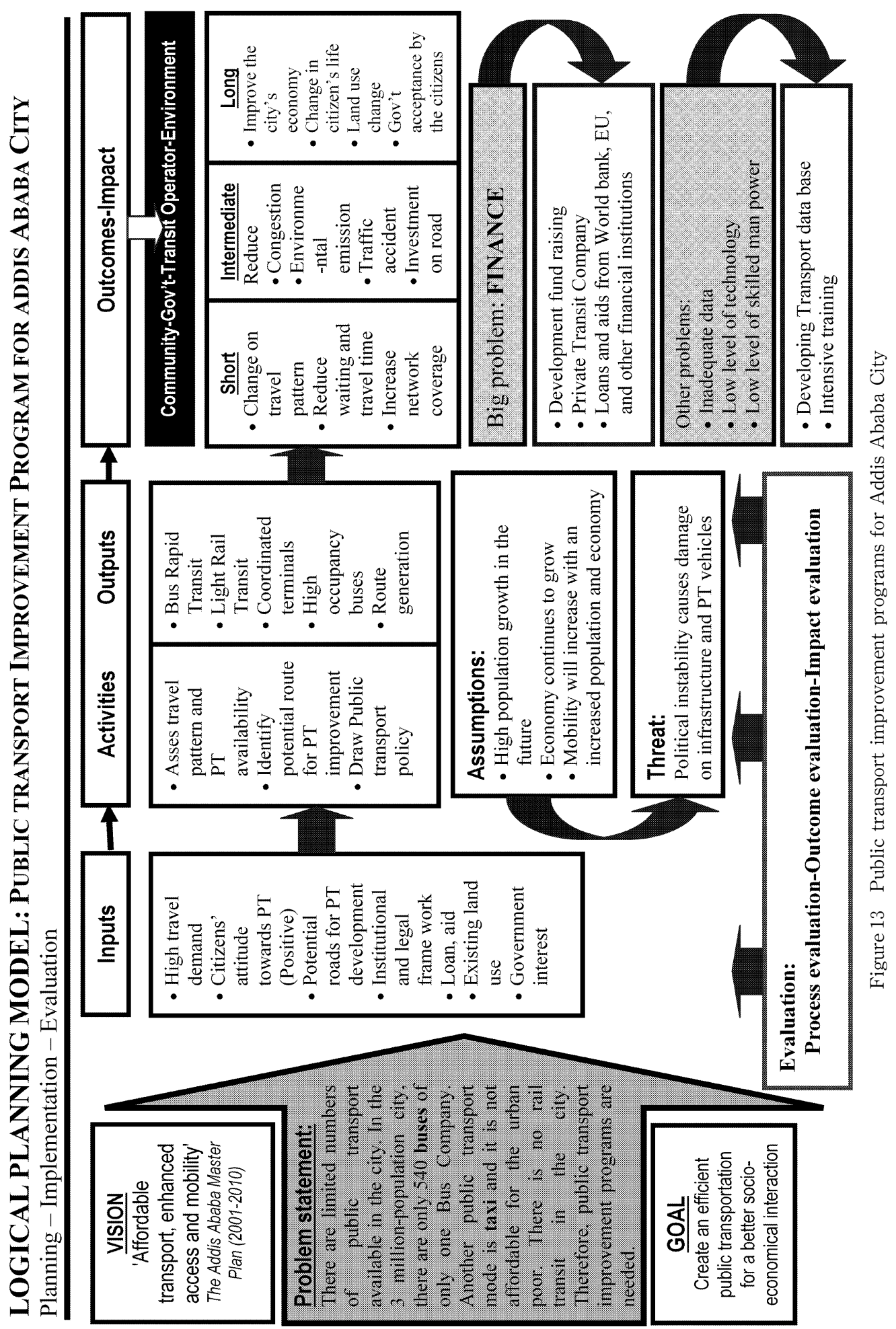


30 minutes to one hour waiting time. With the new system, the frequency will be shortened and a maximum of 10-minute frequency is expected. The in-vehicle time will also be reduced because of a separate lane functioning of BRT and LRT.

Land use : The desirable land development will come up with the development of the new PT system. Commercial and residential developments will emerge along the routes as well as around the terminals and stations. This will lead the city to grow in a well-developed multi nuclei city system.

Transit operators: Though the capital investment is very high, the medium and long-term benefit will be enormous. The transit operators will incur profit from the new PT in a long run. Increasing numbers of passengers, optimizing total system cost and increasing bus and Rail Company's cost recovery system are the expected outcomes.

Government: The new PT improvement and development will be a great success for the government and its acceptability by the public will increase. This will in turn bring about political stability. The public sector's production will increase. As transportation is the backbone of the city development, the economy of the city will be increased. In addition, it is expected that PT would result in savings in investment on road construction and maintenance. This would result in considerable savings to the national and regional economy.

Socio-environment outcomes : Implementation of the PT system is expected to bring about a reduction in the accident rate in the city. According to traffic police data, the total number and type of road accidents in Addis Ababa city in 2004-05 was 10,189, of which 305 were fatal accidents, 563 were major injury accidents, 1,482 were light injury accidents and 7,839 were property damage accidents. The new PT system would also help in bringing down pollution levels in the city, as it would reduce personalised modes on the road.

\section{Discussion}

Because Traffic and transportation problems are numerous and multi facets in the city of Addis Ababa, Logical Planning Model is useful technique as it deals with the interaction of different issues. Logical Planning Model is chosen for Addis Ababa city public transport improvement programs because it is a beneficial evaluation tool that facilitates effective program planning, implementation and evaluation. It gives the image of the current situation and the desired outcome that the public transportation improvement program would achieve. The activities to be performed to cause the desired improvement or change, the resource needed to achieve the desired outcome and the interaction between the potentials and constraints are included in the logical planning process (figure 13). It follows a straight sequence yet capable of solving or representing the complicated process. The baseline input for the Logical Planning Model is the high rate of growth in terms of population and physical extent causes high travel demand, which, as a result, calls for the introduction of a welldeveloped public transportation system. Public transportations are the preferable means of transportation in Addis Ababa, due to low economic condition of its residents. The citizens' attitude survey is evident of this very fact. Apart from economic reasons, environmental advantages also make public transport the preferable over other modes. Therefore, providing quality bus transportation and introducing Light Rail Transit are essential as a part of transportation planning and management. There is also an increased pollution level because 
of increased number of vehicles in the city. Congestion, the absence of an explicit and comprehensive public transport policy and unviable bus service cause inefficient PT service. Inadequate and poorly managed terminals and stops foster inconvenience and discomfort for Bus and taxi users. The existing bus company is not financially sustainable and it is being managed under the city council. The government controlled costing system is not convenient for decision-making within the company. Shortage of finance and the reduction of government subsidy are the grand threats. The absence of well-defined performance parameters to evaluate the operational efficiency of the bus company is a constraint for development. The absence of an up-to-date structure in the enterprise, finance and a low salary scale that foster a lack of skilled manpower are the biggest challenge for the improvement of the service. The potential prospect is the year-to-year increase of the number of bus users.

Taxis, though playing a significant role in rendering service for the community, have many constraints in their operation including excessive fare and high accident rate.

Having these problem statements in mind the input condition is set to be high travel demand, promising institutional framework, financing possibilities and the people's positive attitude and government's interest towards improving the existing PT service. Besides, the urban form and city's development structure are triggered for transportation development as proposed by the Addis Ababa master plan project. The target population and year are set to be 5.6 million populations in the year 2020. With population and travel demand growth, continuing with only the existing road based bus and taxi system will not be viable in solving the city's transportation problems. Thus, Bus Rapid Transit and Light Rail Transit developments are proposed and the route generation was made and then their outcomes and impacts were analysed. The introduction of PT improvement programs will change the travel pattern by reducing waiting and travel time. In the intermediate and long term it reduces congestion, accident and environmental problems. In addition to these, it reduces investment on road construction and maintenance and optimizes the total traffic system. The main constraint is identified to be finance even though there are other constraints such as lack of technology and skilled manpower and lack of information and database. However, there are potentials and these include the participation of international financial institutions like the World Bank and EU. Development fund raising and attracting the private companies in the transit industry is recommended in this study. In addition, there are potentials such as new economic development policies and programs, the availability of a well conceived and detailed city development plan up to 2010, which could be extended in all details. The identified threat for PT development is the frequently occurred political turmoil that causes damage on buses and other infrastructures.

\section{Conclusion}

In a situation where the planning of a project faces numerous problems and constraints, the model that provides stakeholders with the sequence of events connecting the demand with the project's desired impact is essential. This research has addressed this issue by describing the merits of using Logical Planning Models for public transportation improvement programs. Logical planning model is effective tool to simulate a multi-dimensional process. 
The Addis Ababa public transportation is functioning under enormous constraints and the there exists excessive demand with a very limited resource so that there is no a one direction solution for the problem. Therefore Logical Planning Model is a beneficial method to perceive the problem clearly and process the planning of the public transport improvement programs. Therefore, this paper signifies the application of planning models in creating a logical linkage in a situation where there are very high demand, the limited supply and complex interconnected problems and issues.

\section{References}

[1] Anbessa City Bus Enterprise, September 2004, 2004-2005 Yearly Report, Addis Ababa (written in Amharic).

[2] Addis Ababa City Transport Authority, December 2004, Strategic Plan for the Year 2004-2006, Addis Ababa (written in Amharic).

[ 3 ] Ethiopian Roads Authority (ERA), Urban Transport Study and Preparation of Pilot Project for Addis Ababa, Consulting Engineering Services Private Limited (India) and SABA Engineering Private Limited Company, Addis Ababa, Ethiopia, August 2005.

[4] Darido, Georges B., Regulation of Road-Based Public Transportation and Strategies for the Developing World. Transportation Research Record: Journal of the Transportation Research Board, No. 1835, TRB National Research Council, Washington DC, 2003, pp. 66-73.

[5] Jacobs G.D., Maunder D.A.C. and Fouracre P.R., Characteristics of Conventional Public Transport Services in Third World Cities, Traffic Engineering and Control, 27(12), pp. 6-11.

[6] Kim Kyeil, February, Transportation Planning Model for State Highway Management : A Decision Support System Methodology to Achieve Sustainable Development, Blacksburg, Virginia, 1998.

[ 7 ] Mey, Michael D. and Mill, Eric J., Urban Transportation Planning, McGraw-Hill Companies inc., New York, 2001.

[8] Mintesnot, G. and Takano, S., Citizen's Attitude, Existing Challenges and Prospects of Bus Transportation in the City of Addis Ababa, Ethiopia, Proceedings of Japanese Society of Civil Engineers, No. 60, 2005.

[9] Asano, Motoki, A Study on Program Evaluation for Road Maintenance by Logic Model, the Case of the Non-Studded-Tire Policy, Journal of Eastern Asia Society of Transportation Studies, Vol 6, 2005, pp. 1076-1088.

[10] Office of the Revision of Addis Ababa Master Plan (ORAAMP), Project Proposal for Addis Ababa Transport Sector, Addis Ababa, Ethiopia, April 2002.

[11] SEMALY Public Transport Consultants, Comments About Prospective Mass Transport System in Addis Ababa City, Addis Ababa, Ethiopia, July 2001.

[12] Rood Timothy, The Local Index of Transit Availability, An Implementation Manual, The Local Government Commission, December 1998.

[13] The World Bank African region scoping study, Urban Mobility in Three Cities, Addis Ababa, Dar es Salam, Nairobi, SSATP Working Paper No. 70, October 2002.

[14] Wright Paul H., J. Ashford Norman, Stammer Robert J., Transportation Engineering : Plan. and Design. 4th ed, 1998.

[15] W.K. Kellogg Foundation, Logical Model Development Guide, W.K. Foundation, 2004. 